Sung, K., Cooper, T., Oehlmann, J., Singh, J. and Mont, O., 2020. Multi-Stakeholder

Perspectives on Scaling up UK Fashion Upcycling Businesses. Fashion Practice, pp.1-20.

\title{
Multi-stakeholder perspectives on scaling up UK fashion upcycling businesses
}

\author{
Kyungeun Sung,b,*, Tim Cooper ${ }^{\mathrm{b}}$, Johanna Oehlmann ${ }^{\mathrm{c}}$, Jagdeep Singh ${ }^{\mathrm{b}, \mathrm{d}}$ \\ and Oksana Mont ${ }^{\mathrm{d}}$
}

${ }^{a}$ School of Design, De Montfort University, Leicester, UK; ${ }^{b}$ School of Architecture, Design and the Built Environment, Nottingham Trent University, Nottingham, UK; ${ }^{c}$ Nottingham Business School, Nottingham Trent University, Nottingham, UK; ${ }^{d}$ The International Institute for Industrial Environmental Economics, Lund University, Lund, Sweden

*School of Design, De Montfort University, Leicester, UK, Kyungeun.sung@dmu.ac.uk Kyungeun Sung (PhD, Sustainable Design) is a VC2020 Lecturer in Product Design at De Montfort University, UK. Her research interests are in sustainable art, design and craft, sustainable consumption and production by upcycling, and design education.

Tim Cooper ( $\mathrm{PhD}$, Sustainable Consumption) is a Professor of Sustainable Design and Consumption at Nottingham Trent University, UK. His research interests are multidisciplinary, embracing design, consumer behavior, business models and public policy, all in the context of environmental sustainability and, especially, product longevity.

Johanna Oehlmann (MSc, Business Management) is a PhD researcher at Nottingham Trent University, UK. Her research broadly focuses on the mesh of designing and entrepreneuring towards new forms of sustainable value.

Jagdeep Singh ( $\mathrm{PhD}$, Industrial Ecology) is a postdoctoral fellow at Lund University, Sweden. His research focuses on environmental evaluation of business model innovation for sustainability in accommodation, mobility and physical goods sectors. His key research areas involve circular economy, upcycling and the sharing economy.

Oksana Mont ( $\mathrm{PhD}$, Engineering) is a Professor in Sustainable Consumption and Production at Lund University, Sweden. Her current areas of interest are sustainable consumption and 
production and sustainable lifestyles. She is also interested in the role of retailers in promoting sustainability of their own operations and along supply chains. 


\title{
Multi-stakeholder perspectives on scaling up UK fashion upcycling businesses
}

\author{
Fashion upcycling, the process of using waste clothing and textiles to create new \\ products, is an alternative to business-as-usual practices which can effectively \\ address concerns on excessive consumption of energy and material resources and \\ use of chemicals in the fashion industry. Scaling up fashion upcycling businesses \\ could enable the transition of the fashion industry towards sustainability. Past \\ studies in fashion upcycling have paid attention to limited aspects of the \\ businesses, and comprehensive synthesis of viewpoints from diverse stakeholders \\ involved in the business is lacking. This paper provides such a synthesis, \\ focusing on the challenges and success factors for expanding (or scaling up) UK \\ fashion upcycling businesses. Twenty three stakeholders in the UK were \\ interviewed. Four different perspectives (by material suppliers, upcyclers, \\ retailers and consumers) on challenges and success factors for scaling up fashion \\ upcycling businesses in the UK as well as suitable actors to take actions for \\ positive change were identified. Common challenges and success factors across \\ stakeholders were highlighted. The paper further discusses theoretical and \\ practical implications of the study.
}

Keywords: fashion; scaling up; sustainability; sustainable business; sustainable consumption; sustainable design; sustainable production; transition; upcycling

\section{Introduction}

The fashion industry causes serious environmental impacts through its consumption of energy and material resources and its use of chemicals (De Brito, Carbone, and Blanquart 2008; WRAP 2011). Alternatives to business-as-usual practices within the fashion industry can effectively address such concerns and will need to involve various actors and operate across a range of scales (Fletcher 2008). Upcycling represents one such alternative that recovers materials, components or products from waste streams rather than using virgin resources for production (Sung, Cooper, and Kettley 2014; Sung 2017). This study aimed to explore upcycling as a promising alternative in the 
fashion industry focusing on the challenges and success factors for expanding (or scaling up) UK fashion upcycling businesses.

\section{Upcycling}

Upcycling is a relatively new term with varied definitions and practices, which is often defined as the material process of retaining high quality in a closed-loop industrial cycle (Emgin 2012; McDonough and Braungart 2013; Martin and Eklund 2011). It is the process of utilizing used or waste materials, components and products (e.g. clothing and textiles in fashion) to create a product of higher quality or value than the compositional elements (Busch 2008; Farrer 2011; Sung et al. 2014; Sung 2017). Upcycling is popularly understood as an umbrella concept incorporating 'creative' forms of repair, reuse, repurpose, refurbishment, upgrade, remanufacture and recycling (Sung, Cooper, and Kettley 2018; 2019b). In theory it extends the lifetimes of products and materials (Cooper 2010; Sung 2017), thereby increasing material efficiency and reducing industrial energy consumption (Allwood et al. 2011; Sung 2017). It reduces solid waste (Bramston and Maycroft 2013; Zhuo and Levendis 2014; Sung 2017). Upcycling businesses have the potential to be financially sustainable (S. L. Han et al. 2016; Sung and Cooper 2015; Teli et al. 2014) and can create employment opportunities, especially for disadvantaged people when upcycling requires minimal skills such as simple redecoration of clothing or fashion items (Cumming 2017; Palmsköld 2015), rather than high level skills such as utilizing latest technology for advanced remanufacturing.

Craft-based upcycling in particular (e.g. creative repair, reuse, repurpose) has long been a part of human life. Until mass production became a common practice in the 19th century, many products were used to the very limits of their utility (Fromm 2013). Mass production introduced new 'virtues' of replaceability and a throw-away mentality in the name of gearing production towards economies of scale (Hawkins 2001). New 
consumerism - with pervasive, conspicuous, status goods and a growing disconnection between consumers' desires and incomes (Schor 2000) - then replaced the pre-modern long-term engagement with a product by frequent replacement purchases of products and subsequent reduction in product quality, sometimes allegedly through planned obsolescence (Packard 1963). With the arrival of the consumer society many useful skills for, for example, maintenance and repair have largely been lost in the western world (Salvia et al. 2015).

The past few years however have seen a revival of the upcycling trend, driven by multiple factors, such as growing concern for the environment in general and specifically for resource scarcity and increasing volumes of waste (Farrant, Olsen, and Wangel 2010). In particular, the emerging circular economy - an alternative to the current linear economy of take-make-use-dispose (Stahel 2016; Ellen MacArthur Foundation 2016) - has been promoting upcycling as one of the strategies that plays a role in slowing and/or closing material cycles (Ellen MacArthur Foundation 2013). Other benefits include creating economic opportunities, stimulating entrepreneurship and supporting the culture of prosumerism (Seravalli 2016). The circular economy has attracted attention from mainstream companies, start-up SMEs (Small- and Mediumsized Enterprises) and creative industries. Despite increased interest and potential benefits for the environment, economy and society, upcycling remains a niche practice. A process of 'scaling up', whereby an initially unusual practice becomes mainstream (Van den Bosch, S. J. M. 2010), is necessary in the case of upcycling to enable the transition of the fashion industry towards sustainability. However, an alternative viewpoint asserts that scaling up upcycling does not necessarily lead to sustainability depending on the processes involved in upcycling which may result in negative net environmental impact. ${ }^{\mathrm{i}}$ 
With increased interest in upcycling in industry, the past decade has seen a surge of publications on upcycling, in disciplines ranging from engineering and management to consumer studies, and the body of literature is growing (Sung 2015). Although research on upcycling is still at its infant stage, existing studies have focused largely on fashion and textiles (e.g. Busch 2008; Fletcher 2008; McCorkill 2014; J. H. Park and Kim 2014; Twigger Holroyd 2012; Cassidy and Han 2013; S. Han, Tyler, and Apeagyei 2015). ${ }^{\text {ii }}$ Previous research in fashion upcycling includes a description of the concept and process (Busch 2008; Fletcher 2008), reflection on the practice (S. Han et al. 2015; McCorkill 2014), design guidelines (J. H. Park and Kim 2014, 138-154) and an exploration of consumers' purchase intentions (H. H. Park 2015). Past studies have paid attention to limited aspects of fashion upcycling businesses and a comprehensive synthesis of viewpoints from diverse stakeholders involved in the business is lacking. This study therefore aimed to provide such a synthesis, focusing on the challenges and success factors for expanding (or scaling up) UK upcycling businesses in the fashion industry.

\section{Transition and scaling up}

As the environmental problems caused by the fashion industry are complex and severe, incremental clean technologies have limits to address such problems (Mair, Druckman, and Jackson 2016). Substantive transition in the fashion industry is required in terms of fundamental changes in the system of production and consumption (Elzen, Geels, and Green 2004; Gardetti and Torres 2013; Niinimäki and Hassi 2011). These fundamental changes include interrelated changes in behavior, technology, environment, rules and regulations, financing systems and perceptions (Van den Bosch, S. J. M. 2010). They are also often referred to as socio-technical transitions as they entail both social changes and technological solutions (Geels 2004; 2010). Socio-technical transitions do not take 
place easily as the existing systems are stabilized by lock-in mechanisms relating to vested interests, sunk investments, favorable subsidies and regulations, or behavior patterns (Geels 2004; Unruh 2000). Socio-technical transitions are therefore often characterized as a non-linear, long-term, complex system-level process (Kemp and Loorbach 2006; Van den Bosch, S. J. M. 2010). One of the widely used frameworks to understand and explain such a process is multi-level perspective (MLP) (Geels and Schot 2007; Geels 2002; Rip and Kemp 1998). MLP uses three levels in a societal system - niche, regime and landscape - as an analytical tool to explain the dynamics of transitions depending on the interactions between the different levels (Geels 2002; Van den Bosch, S. J. M. 2010). The regime is dominant structure, culture and practices in fulfilling the societal need (e.g. mass production based on raw materials that dominates the production domain). Niches are societal sub-systems that provide alternatives to the regime (i.e. new, sustainable practices and related culture and structure). The landscape is the environment of the societal system encompassing large-scale and long-term developments such as demographics, international politics or worldviews (Ceschin 2012; Geels 2002; 2010; Van den Bosch, S. J. M. 2010).

In transition studies, scaling-up is understood as the dynamic process of transitioning from niche (practices) to mainstream/regime (practices) in the multi-level perspectives (de Haan and Rotmans 2011; Smith 2007). "Through scaling-up, a new or deviant constellation of structure, culture and practices attain more influence and stability and increases its share in meeting a societal need. [...] The outcomes of scaling-up are fundamental changes in the dominant way societal needs are fulfilled." (Van den Bosch, S. J. M. 2010, p.68). In other words, scaling-up is the process in which initially deviant or unusual (sustainable) practices, structure or culture become increasingly dominant or mainstream. 


\section{Methods}

Semi-structured interviews were chosen to provide some level of structure, allowing freedom in the sequencing and wording of questions (Robson 2011) while giving the interviewer an opportunity to probe when necessary (Rabionet 2011). In the UK, upcycling businesses are niche and mostly small or micro in size $\mathrm{i}^{\mathrm{iii}}$. Twenty-three stakeholders of fashion upcycling SMEs were interviewed between April and June 2017. All nineteen interviews with twenty-three interviewees were conducted either in person or via telephone depending on the interviewee's preference and availability. The interviews typically lasted between 30 minutes and 60 minutes.

\section{Sampling}

Dimensional sampling - using various dimensions important to the study (Robson 2011) - was used to recruit interviewees. The first dimension was type of stakeholders. Key stakeholders in upcycling businesses were assumed to be material suppliers, upcycling designers and makers, retailers and consumers. Within consumers, gender and age dimensions were used. Two gender groups (female and male) and three age groups (under 35, between 35 and 54, and between 55 and 64) were selected to have a minimum of six interviewees.

To identify relevant UK practitioners, internal expert interviews (with project team members as subject experts), retailer lists in Remade in Britain (a UK-based online upcycling marketplace), and keywords-based search (with keywords such as "upcycling", “furniture”, “charity", “vintage”, “craft fairs”, "retail”, “scrap store”, "reuse center", "waste exchange", and "UK" for creating keyword combinations) were utilised in March 2017. Ninety-eight material suppliers, 134 upcycling enterprises and 70 retailers were contacted via email. For the recruitment of consumers, convenience 
sampling - based on convenient accessibility and proximity to the researcher (Robson 2011) - was employed.

\section{Participants}

Interview participants $(n=23)$ were sixteen practitioners (two material suppliers, two supplier-retailers, one upcycler, ten upcycler-retailers, and one retailer; in other words, four suppliers, eleven upcyclers and thirteen retailers) and seven consumers. Overall, sixteen were female and seven male. Three were under 35 years, ten were between 35 and 54 years, and another ten between 55 and 64 years. Most were British $(n=19)$ and had completed higher education $(n=20)$. Their occupational or study areas were predominantly art and design $(\mathrm{n}=12)$ or business $(\mathrm{n}=7)($ Table 1$)$.

Table 1. Socio-demographic characteristics of interview participants

\begin{tabular}{|c|c|c|c|}
\hline \multirow{2}{*}{\multicolumn{2}{|c|}{ Interviewee characteristics }} & \multicolumn{2}{|c|}{ Frequency } \\
\hline & & Practitioners $(n=16)$ & Consumers $(n=7)$ \\
\hline Gender & Female & $12(75 \%)$ & $4(57.2 \%)$ \\
\hline Age group & $\begin{array}{r}\text { Under } 35 \\
35 \text { to } 54 \\
55 \text { and over }\end{array}$ & $\begin{array}{c}1(6.25 \%) \\
7(43.75 \%) \\
8(50 \%)\end{array}$ & $\begin{array}{l}2(28.6 \%) \\
3(42.8 \%) \\
2(28.6 \%)\end{array}$ \\
\hline Nationality & $\begin{array}{r}\text { British } \\
\text { Italian } \\
\text { Australian } \\
\text { Belgian }\end{array}$ & $\begin{array}{l}12(75 \%) \\
2(12.5 \%) \\
1(6.25 \%) \\
1(6.25 \%)\end{array}$ & $\begin{array}{c}7(100 \%) \\
0(0 \%) \\
0(0 \%) \\
0(0 \%)\end{array}$ \\
\hline Education & $\begin{array}{r}\text { Secondary } \\
\text { Further } \\
\text { Higher }\end{array}$ & $\begin{array}{c}2(12.5 \%) \\
1(6.25 \%) \\
13(81.25 \%)\end{array}$ & $\begin{array}{c}0(0 \%) \\
0(0 \%) \\
7(100 \%)\end{array}$ \\
\hline $\begin{array}{l}\text { Occupation / } \\
\text { study areas }\end{array}$ & $\begin{array}{r}\text { Art and design } \\
\text { Business } \\
\text { Construction } \\
\text { Miscellaneous* }\end{array}$ & $\begin{array}{c}10(62.5 \%) \\
6(37.5 \%) \\
0(0 \%) \\
0(0 \%)\end{array}$ & $\begin{array}{l}2(28.6 \%) \\
1(14.2 \%) \\
2(28.6 \%) \\
2(28.6 \%)\end{array}$ \\
\hline
\end{tabular}

* Miscellaneous occupational or study areas were sustainable development and occupational therapy.

Half of the practitioners were sole traders ( $n=8$, all upcyclers), five were registered charities (two material suppliers, one upcycler and two retailers), two limited companies (upcyclers), and one partnership (material supplier). Their size of the 
business was mostly micro $(n=15)$ : thirteen of them had less than five employees and two had between five and eight. One was small size (number of employees: 34). Annual turnover of micro businesses ranged between $£ 1,000$ (part-time, hobby business) and $£ 90,000$, with the average of $£ 25,800$. The small business’ turnover was $£ 650,000$.

\section{Interview procedures and questions}

As there were two researchers conducting interviews, an interview schedule was prepared with questions and anticipated answers in order to get consistent and compatible results throughout all interviews. The first three interviews (with one material supplier, one upcycler and one consumer) were used as a pilot study to ensure the reliability and validity of the study. During the pilot study, each interview was conducted by one researcher and the other researcher played a role as an observer. Two researchers took turns, discussed question wordings, sequences and manners, and made any necessary adjustment (e.g. change of question orders and clarification of certain expressions).

During the interview, interviewees were first asked about socio-demographic information (i.e. age, nationality, occupation and highest education level and study/work area). Business information was asked next (i.e. legal status, number of employees, annual turnover). Main questions were about challenges and success factors for scaling up fashion upcycling businesses in the UK and suitable actors for making changes. See Table 2 for all questions. All interviews were fully audio-recorded with the consent of all the participants.

Table 2. Main interview questions

\begin{tabular}{c|l|l}
\hline Category & \multicolumn{1}{|c|}{ Stakeholder } & \multicolumn{1}{c}{ Question } \\
\hline Challenges & Material suppliers & $\begin{array}{l}\text { What are the challenges in increasing supplies of } \\
\text { suitable materials for customers (upcycling } \\
\text { businesses)? }\end{array}$ \\
\hline
\end{tabular}




\begin{tabular}{l|l|l}
\hline \multirow{2}{*}{$\begin{array}{l}\text { Upcycling } \\
\text { designers and } \\
\text { makers }\end{array}$} & $\begin{array}{l}\text { What are the challenges in expanding/growing your } \\
\text { business? }\end{array}$ \\
\cline { 2 - 3 } & Retailers & $\begin{array}{l}\text { What are the challenges in selling more upcycled } \\
\text { products? }\end{array}$ \\
\cline { 2 - 3 } & Consumers & $\begin{array}{l}\text { What are the challenges in trying to buy more upcycled } \\
\text { products? }\end{array}$ \\
\hline \multirow{2}{*}{$\begin{array}{l}\text { Key } \\
\text { challenges }\end{array}$} & All stakeholders & Which challenge is the biggest one? \\
\hline \multirow{2}{*}{$\begin{array}{l}\text { Success } \\
\text { factors }\end{array}$} & $\begin{array}{l}\text { Upcycling } \\
\text { designers and } \\
\text { makers }\end{array}$ & $\begin{array}{l}\text { What help do you need to increase supplies of suitable } \\
\text { materials for customers (upcycling businesses)? }\end{array}$ \\
\cline { 2 - 3 } & Retailers & What help do you need to expand/grow your business? \\
\cline { 2 - 3 } & Consumers & What help do you need to sell more upcycled products? \\
\hline $\begin{array}{l}\text { Suitable } \\
\text { actors }\end{array}$ & All stakeholders & Who needs to act to make changes? \\
\hline $\begin{array}{l}\text { Key success } \\
\text { factors }\end{array}$ & All stakeholders & $\begin{array}{l}\text { Which help/idea/solution would be the most important } \\
\text { one? }\end{array}$ \\
\hline
\end{tabular}

\section{Analysis}

All interview recordings were transcribed by an independent transcription service. The transcripts were anonymized and entered into QSR NVivo 10 software and analyzed. A thematic analysis - an approach to identifying, analyzing and interpreting patterned meaning or themes in qualitative data (Braun, Clarke, and Terry 2014) - was conducted, with each transcript examined line by line. Grounded codes were identified and constantly revised to fine-tune the coherent, collective themes.

\section{Results}

The results section describes different perspectives on challenges and success factors for scaling up UK fashion upcycling businesses by material suppliers, upcycling designers and makers, retailers and consumers.

\section{UK material suppliers' perspectives}

The interviewed material suppliers (e.g. scrap stores) identified four main challenges.

The first challenge was in keeping a steady inflow of sufficient, affordable (or free) 
materials. One supplier especially commented on the potentially decreasing number of material donations by companies as they might want to sell the materials in a reuse market. The second challenge was complicated laws and legislations involving excessive paperwork. One stated, "Because it is so complicated, we cross lots of laws to do with waste and waste transfer, VAT, weights and measures. It's all bound up and it gets really complicated sometimes. So complicated that the law seems to contract itself. And sometimes we don't know which law that we should kind of go, 'okay, this is the one that we follow'." Another said, "[...] the way that companies now have to dispose of their waste, it's very complicated. [...] Some of them just completely freak out and go, 'oh, no, no, we can't give it to you because we need to fill this paperwork in and we need to do this and that'." The third challenge was in being financially sustainable. One charity organization mentioned the difficulty in acquiring funding, as put by one, “[...] being a charity that saves the planet doesn't seem to be enough now. [...] We asked the big lottery for funding and they've said 'No, you don't do enough for the community to be eligible for our funding," The fourth challenge was macro-economic situation. For example, one supplier saw a recession as a double-edge sword for them. She said, "If there's a recession, the companies that we deal with [that donate materials] are under threat, but our takings go up because more people are looking for cheaper options because they have less money. So I am kind of looking forward to a recession and kind of not."

The success factors were identified as: awareness raising, legal and legislative support, and financial support. Material suppliers would like to see promotion of their organizations to a wider range of local and regional companies such that they could get more donations. They would also like to have a special organization or a group of experts to help with the laws and legislations involved in reutilizing materials. Financial 
support would be desirable mostly to provide support with the lease or rent. Individual activists and volunteers were seen as potential actors to promote material suppliers. National organizations such as Reuseful UK were regarded as being responsible for legal and legislative support as well as liaison between different material suppliers. Local councils were viewed appropriate for lease/rent support. Various companies could also be financial supporters.

\section{UK upcycling designers and makers' perspectives}

Upcycler interviewees identified four main areas of challenge: sourcing materials, production, marketing and space. When sourcing materials, access to a variety of affordable, used materials with quality and quantity could be a challenge. Finding certain parts (e.g. magnetic catch for jewelry) could be a difficult job too. During the production, limitation from the given materials (e.g. particular shapes of clothing), finding right equipment, and time-consuming handmade process could be major challenges. In particular, the consequences of time-consuming handmade process include a small volume of production, a limited product variety and high labor cost. In marketing, having limited opportunities to expose their products and build (brand) reputation was viewed as the most important challenge. High price for sales and high cost for attending markets and fairs were also regarded as major challenges. Regarding the cost for attending markets or fairs, in addition to general travel and transport expense, commission was the main culprit. One upcycler said, "We have people that occasionally contact us from different galleries and offer to sell our stuff but they want $40 \%$ to $50 \%$ commission. And that is an awful lot and how do we do that?" In terms of space, affordability of the space and the trade-off between affordability and access to customers were highlighted (especially in London). One stated, "In London it [affordability of space] is a big thing at the moment. A lot of professionals [...] they 
moved out completely of London [...] Obviously, if you are somewhere else, it's going to be more difficult to deal with customers because customers need to come to you." A lack of space was also mentioned. Other miscellaneous challenges were market situation (e.g. changing consumers' demand), demanding multiple roles required to run a business (e.g. as a manager, marketer, etc. as well as a designer or maker), and a lack of motivation (i.e. no intention to grow the business).

Largely, support for human resources, marketing, finance and general resources as well as keeping up with the market and trend were stated as success factors. Interestingly, interviewees did not mention any success factors related to sourcing materials. In terms of human resources, upcycling designer and makers believed that having employees or apprentices (for production) and office assistants (especially to deal with online orders) would be helpful to scale up their business. In marketing, online marketing support, connections with right customers/buyers, and press coverage for building brand reputation were identified as success factors. Regarding the press coverage, one upcycler stated, "We know we have a good product. We know we have an original product. We know that with the small exposure we've been very successful with the limited things that we've done. So we know if we can get some exposure, it will grow.” Financial support was regarded as an important success factor by many for marketing, improving the working environment, and training (also hiring) people. General resources that upcyclers needed were mostly time. One upcycler pointed to the importance of keeping up with ongoing trends and change of market in order to be competitive. When it comes to potential actors to make changes, upcycling entrepreneurs either took responsibility for themselves or were not sure about the answer. One said, “Me. I have to help myself. And that's why I am going to university because I am not quite sure how to do it [scaling up business]." 


\section{UK retailers' perspectives}

Retailer interviewees identified seven areas of challenges: product, marketing, physical shop, finance, consumers and macro-economic situation. The challenge in product was about the quality of products (i.e. saleability). Marketing challenges included the difficulty in: a) getting the right narratives and keywords, b) using social media effectively for promotion purposes, c) attracting suitable consumers, and d) finding the time to do market research. About the right narratives, one retailer said, "It's getting the narrative right when you are actually promoting your product for people to understand, because people look at things and [...] say, 'Oh, what's that?' They don't recognize it." For the physical shop, the challenge was in having a shop with sufficient display space in a good location (e.g. on the high street) with affordable rent. A lack of funding (e.g. for outsourcing a photographer) was the financial challenge. Consumers' beliefs about upcycling and upcycled products were identified as one of important challenges. For example, some consumers might undervalue the skills and efforts used to upcycle items (i.e. underestimating the value of handcraft) or have negative perception on upcycled products (e.g. less valuable products from cheap/free materials). Macro-economic situation could become a challenge (e.g. restricted consumer expenditure due to the stagnating economy).

For the success factors to increase the sales of upcycled products, three areas have been pinpointed: product, marketing and consumers. In product, high quality (i.e. aesthetics, longevity, desirability) and availability of the upcycled products were viewed as success factors. In marketing, the essence was good exposures of the shop and products to increase sales, and for this, detailed strategies were suggested such as effective online marketing, good story/history behind products, right wording, good product photos, good product reviews and celebrity involvement in promotion. Regarding consumers, raising awareness (e.g. environmental cost of mass-produced 
products), building trust (that what they pay for is worth) and increasing appreciation of the skills and time for upcycling were viewed important. The retailers felt responsible for guaranteeing the availability and high quality of the upcycled products. For marketing and public education (for increasing awareness and appreciation of the upcycled products), social media, celebrities, consumers and volunteers were considered as important actors to spread the word.

\section{UK consumers' perspectives}

Consumer interviewees (with purchasing intentions) identified five areas of challenges to buy more upcycled products: product, price, purchasing experience, awareness (and understanding) and personal situation. There were four product-related challenges. The biggest product-related challenge appeared to be limited availability of upcycled products. One consumer said, "You can't get what you specifically would like because there's not enough of it out there." and another stated, “There's not that much locally available. [...] They are one-offs, so you know, you have to get in there quickly or it's gone." Other product-related challenges were difficulty in finding good-quality products, limited suitability (e.g. upcycled one-off clothes in your size) and warranty unavailability. High price was another important challenge. Even if the price was not high, price justification was still an issue, as put by one interviewee, "If you look at it and think you could do that job by yourself, I personally find it harder to justify spending the money." In terms of purchasing experience, limited access to the upcycled products and inconvenience in shopping were the main challenges. One said, "It's so easy to buy, and so cheap to buy new stuff now. [...] But if you want something upcycled, you are probably gonna have to spend a bit more time and do a bit more research to find the independent people who are doing it." Regarding awareness and understanding, consumer interviewees pointed out a lack of awareness about the 
environmental impact of current mass production and upcycling as an alternative as well as loss of appreciation or understanding of the value of handmade products and processes. Personal situation (e.g. financial situation) could also be a challenge.

Success factors to enable and encourage consumers to buy more upcycled products were related to product, price, purchasing experience, and awareness and understanding. Bespoke upcycling was suggested as a good strategy to increase sales, as put by one, "I do like the idea of maybe being able to take things that I had chosen second hand to have them upcycled to specifically what I want because maybe some upcycling [...] can be a nice job but it's not exactly what you were looking for." Lowering the price by VAT (Value-Added Tax) reduction could also help sales. Regarding purchasing experience, suggestions were mostly about increasing availability of and access to upcycled products. More physical shops should be available locally, ideally embedded in local shopping environment, such that "You can go in. You can touch them. You can feel them. You can try them on. You can see if you like them.” One-stop shop (where upcycled goods are available for most fashion products) could also help consumers to experience and purchase a variety of upcycled products. In order to have more physical shops or increase the number of available upcycled products, financial support and incentives for companies were suggested (e.g. lease support for retailers selling upcycled products, or incentives or grants for designers, makers or manufacturers upcycling pre- and post-consumer wastes). For increased awareness and understanding, more information, training and education were suggested (on, for example, current waste and resource depletion issues as well as new alternatives to current production and consumption system including upcycling). When asked about the suitable actors to make positive changes to realize the success factors identified, consumer interviewees showed the most holistic approach amongst all stakeholders. 
Two of them answered all actors including consumers, designers and makers, businesses and government. They said that businesses should be responsible for transforming their business-as-usual to more sustainable ways (e.g. incorporating upcycling as part of their manufacturing, or indicating whether or not any good has been made through upcycling). Media companies should help spread words about upcycling. The government should provide financial support (e.g. tax reduction, grants, incentives) for research, initiatives and businesses related to upcycling. Local councils could also become funders and supporters of local SMEs based on upcycling. The interviewees also pointed out their own responsibilities for being a responsible consumer.

\section{Discussion and conclusions}

There appeared to be common challenges across stakeholders. Both material suppliers and upcyclers found sourcing materials difficult, which calls for a systemic approach to circulation of materials (from companies and consumers to material suppliers, to upcyclers, and back to companies and consumers). The need for improved material provision has also been emphasized by other studies addressing household upcycling (Sung, Cooper, and Kettley 2019a; 2019b) and varied upcycling entrepreneurs (Sung et al. 2017). Both material suppliers and retailers mentioned that financial sustainability and macro-economic situation are important factors. Finance has been regarded as a typical challenge amongst small fashion entrepreneurs in many countries including UK, Australia and Finland (Craik 2015; Gu 2014; Aakko and Niinimäki 2018). Both upcyclers and retailers perceived ineffective marketing and a lack of suitable space as main challenges. Time-consuming marketing and need for sufficient space to store materials and keep essential equipment have been typical challenges in hand-made or craft businesses (Rosner and Ryokai 2009; Dissanayake, Perera, and Wanniarachchi 2017; Jaitly 1989; Tung 2012). Retailers and consumers found it difficult to obtain good 
quality upcycled products with limited availability. This issue of product quality and availability is a unique challenge in upcycling businesses. Consumers' lack of awareness and negative beliefs and perceptions about upcycling and upcycled products were identified by retailers and consumers. This awareness/perception of challenge is another unique challenge in upcycling businesses. Such dislike towards the products from used/waste materials (i.e. preference towards the mass-produced from new materials) could be regarded as one of the important lock-in mechanisms (Geels 2004). Another notable lock-in mechanism is legislation which hinders material donations by companies. Although this was mentioned only by material suppliers, as it affects the whole material cycles, it should be treated as a significant challenge which needs to be addressed (Table 3 ).

There were common perceived success factors across stakeholders: a) awareness raising activities such as promotion, information, training and education (identified by material suppliers, retailers and consumers); b) financial support (material suppliers, upcyclers and consumers); c) support for marketing (upcyclers and retailers); and d) increased availability of and access to the upcycled products (retailers and consumers) (Table 3). Community workshops and events, TV and inspirational media, education, and financial incentives for upcycling businesses and initiatives have also been suggested as promising interventions for scaling up upcycling in UK households (Sung et al. 2019a). The multiple success factors imply that interrelated changes are required in perceptions, behaviors, financing systems and environment in order to scale up fashion upcycling SMEs. Such changes could be made through appropriate interventions tackling different socio-technical issues simultaneously involving multiple stakeholders and actors at various levels and scales, leading to fundamental changes in 
the system of production and consumption (Elzen and others 2004; Van den Bosch, S. J.

M. 2010; Sung et al. 2019a).

Table 3. Common challenges and success factors across stakeholders

\begin{tabular}{|c|c|c|c|}
\hline \multicolumn{4}{|c|}{ Challenges } \\
\hline Material suppliers & Upcyclers & Retailers & Consumers \\
\hline $\begin{array}{ll}\text { - } & \text { Sourcing } \\
\text { materials* } \\
\text { - } & \text { Legislation } \\
\text { - } & \text { Finance } \\
\text { - } & \text { Macro economy }\end{array}$ & $\begin{array}{ll}\text { - } & \text { Sourcing } \\
\text { materials } \\
\text { - } & \text { Production issues } \\
\text { (e.g. equipment, } \\
\text { labor) } \\
\text { - } \text { Marketing } \\
\text { - } \quad \text { Space } \\
\text { - } \text { Market situation } \\
\text { - } \text { Multiple roles } \\
\text { - } \text { Lack of } \\
\text { motivation }\end{array}$ & 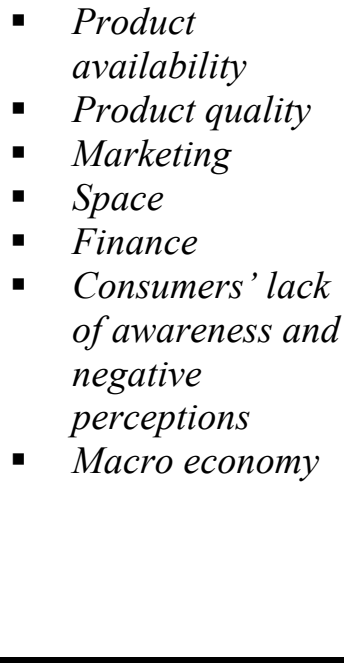 & $\begin{array}{ll}\text { - } & \text { Product } \\
\text { - } & \text { Pvailability } \\
\text { - } & \text { Product quality } \\
\text { - } & \text { Suitability } \\
\text { - } & \text { Price } \\
\text { - } & \text { Purchasing } \\
\text { - } & \text { A lack of } \\
& \text { awareness and } \\
\text { negative } \\
\text { perceptions } \\
\text { Personal } \\
\text { situation }\end{array}$ \\
\hline \multicolumn{4}{|c|}{ Success factors } \\
\hline Material suppliers & Upcyclers & Retailers & Consumers \\
\hline $\begin{array}{l}\text { - Awareness } \\
\text { raising } \\
\text { Legal and } \\
\text { legislative } \\
\text { support } \\
\text { Financial } \\
\text { support }\end{array}$ & $\begin{array}{ll}\text { - } & \text { Human resources } \\
\text { - } & \text { Marketing } \\
\text { - } & \text { Financial } \\
\text { - } & \text { Gupport } \\
\text { General } \\
\text { resources } \\
\text { - } \text { Keeping up with } \\
\text { trends/market }\end{array}$ & $\begin{array}{l}\text { - } \quad \text { Product quality } \\
\text { - } \quad \text { ancreased } \\
\text { availability } \\
\text { - } \text { Marketing } \\
\text { - } \text { Awareness } \\
\text { raising }\end{array}$ & $\begin{array}{ll}\text { - } & \text { Bespoke product } \\
\text { - } & \text { Lowered price } \\
\text { - } & \text { Increased } \\
& \text { availability } \\
\text { - } & \text { Financial } \\
\text { support for } \\
\text { businesses } \\
\text { - Awareness } \\
\text { raising }\end{array}$ \\
\hline
\end{tabular}

* Italics highlight the common challenges and success factors

Overall, most challenges and success factors identified from the fashion upcycling designers and makers in SMEs are identical with those from upcycling entrepreneurs with varied inputs (waste materials) and outputs (upcycled products) (Sung et al. 2017). It implies that upcycling SMEs may share common challenges and success factors regardless of the sector (or main waste material categories or production outputs). In addition to corroborating the previous research by Sung et al. (2017), this paper provided additional challenges and success factors from material suppliers, retailers and consumers such that one could have a holistic view on the supply chain of 
upcycling SMEs. As highlighted by Sung et al. (2017), success factors that are particularly significant for upcycling SMEs are the provision of used/waste materials with quality and quantity, skills development for high quality upcycling, education and communication to change consumers' beliefs, and policies and regulations to encourage more reuse, repair and upcycling. One unique addition from this paper could be bespoke upcycling services.

Although this paper captured limited perspectives from twenty-three stakeholders in the UK, it partially corroborated the previous research, proving validity and reliability of the study to some extent. If this study were repeated in other countries, the results may be different from what has been presented in this paper to a varying extent, depending on similarities/differences between the UK and the other country in terms of economic, political, cultural, social, demographic and technological aspects. The paper has provided new information on perceived challenges and success factors for scaling up upcycling SMEs by extended stakeholders (not only upcyclers but also material suppliers, retailers and consumers). The findings could be used for direct stakeholders (material suppliers, upcycling designers and makers, retailers and consumers) and indirect stakeholders (central government, local councils, other businesses, activists, etc.) to take actions for scaling up upcycling SMEs in fashion (and in other sectors) towards sustainability. It is also the authors' hope that this paper inspires and informs academic researchers and various practitioners to promote upcycling in their areas to raise awareness and increase understanding of upcycling by the public.

\section{Disclosure statement}

No potential conflict of interest was reported by the authors. 


\section{Acknowledgements}

The work was supported by the Engineering and Physical Sciences Research Council (EPSRC) funded Centre for Industrial Energy, Materials and Products, grant reference EP/N022645/1; Nottingham Trent University (NTU)-Materials Research Seed-Corn Fund; De Montfort University (DMU)-VC2020 Fund; and Urban Reconomy by Formas 211-2014-1440. We acknowledge Research and Innovation Allowance at DMU for manuscript writing, and thank Stuart Lawson, Kelley Wilder, Siobhan Keenan, Deborah Cartmell and Rusi Jaspal at DMU for supporting this research. Many thanks to Lynn Oxborrow, Mollie Painter-Morland and Usha Ramanathan at NTU for their advice and initial inputs.

\section{References}

Aakko, Maarit and Kirsi Niinimäki. 2018. "Fashion Designers as Entrepreneurs: Challenges and Advantages of Micro-Size Companies." Fashion Practice 10 (3): 354-380.

Allwood, Julian M., Michael F. Ashby, Timothy G. Gutowski, and Ernst Worrell. 2011. "Material Efficiency: A White Paper." Resources, Conservation and Recycling 55 (3): $362-381$.

Bramston, David and Neil Maycroft. 2013. "Designing with Waste." In Materials Experience: Fundamentals of Materials and Design, edited by Elvin Karana, Owain Pedgley and Valentina Rognoli, 123-133. Oxford: Elsevier.

Braun, Virginia, Victoria Clarke, and Gareth Terry. 2014. "Thematic Analysis." Qual Res Clin Health Psychol 24: 95-114.

Busch, Otto von. 2008. "Fashion-Able. Hacktivism and Engaged Fashion Design." PhD diss., School of Design and Crafts; Högskolan för design och konsthantverk.

Cassidy, Tracy D. and Sara L. Han. 2013. "Upcycling Fashion for Mass Production." In Sustainability in Fashion and Textiles: Values, Design, Production and Consumption, edited by Miguel Angel Gardetti and Ana Laura Torres, 148-163. London: Routledge. 
Ceschin, Fabrizio. 2012. "The Introduction and Scaling Up of Sustainable ProductService Systems. A New Role for Strategic Design for Sustainability”. PhD diss., Politecnico di Milano.

Cooper, Tim, ed. 2010. Longer Lasting Products. Abingdon: Routledge.

Craik, Jennifer. 2015. "Challenges for Australian Fashion." Journal of Fashion Marketing and Management 19 (1): 56-68.

Cumming, Deb. 2017. "A Case Study Engaging Design for Textile Upcycling." Journal of Textile Design Research and Practice 4 (2): 113-128.

De Brito, Marisa P., Valentina Carbone, and Corinne Meunier Blanquart. 2008. "Towards a Sustainable Fashion Retail Supply Chain in Europe: Organisation and Performance." International Journal of Production Economics 114 (2): 534553.

de Haan, J. Hans and Jan Rotmans. 2011. "Patterns in Transitions: Understanding Complex Chains of Change." Technological Forecasting and Social Change 78 (1): $90-102$.

Dissanayake, DGK, Srimala Perera, and Thushari Wanniarachchi. 2017. "Sustainable and Ethical Manufacturing: A Case Study from Handloom Industry." Textiles and Clothing Sustainability 3 (1): 1-10.

Ellen MacArthur Foundation. "Circular Economy.", http://www.ellenmacarthurfoundation.org.

Ellen MacArthur Foundation . 2013. Towards the Circular Economy: Economic and Business Rationale for an Accelerated Transition: Ellen MacArthur Foundation.

Elzen, Boelie, Frank W. Geels, and Kenneth Green. 2004. System Innovation and the Transition to Sustainability: Theory, Evidence and Policy Edward Elgar Publishing.

Emgin, Bahar. 2012. "Trashion: The Return of the Disposed." Design Issues 28 (1): 6371.

European Commission. "What is an SME?", http://ec.europa.eu/growth/smes/businessfriendly-environment/sme-definition_en.

Farrant, Laura, Stig Irving Olsen, and Arne Wangel. 2010. "Environmental Benefits from Reusing Clothes." The International Journal of Life Cycle Assessment 15 (7): 726-736. 
Farrer, Joan. 2011. "Remediation: Discussing Fashion Textiles Sustainability." In Shaping sustainable fashion: changing the way we make and use clothes, edited by Alison Gwilt and Timo Rissanen, 19-34. London: Earthscan.

Fletcher, Kate. 2008. Sustainable Fashion and Textiles: Design Journeys. London: Earthscan.

Fromm, Erich. 1976. To have Or to be? London: Bloomsbury.

Gardetti, Miguel A. and Ana L. Torres, eds. 2013. Sustainability in Fashion and Textiles: Values, Design, Production and Consumption. London: Routledge.

Geels, Frank W. 2004. "From Sectoral Systems of Innovation to Socio-Technical Systems: Insights about Dynamics and Change from Sociology and Institutional Theory." Research Policy 33 (6): 897-920.

Geels, Frank W 2010. "Ontologies, Socio-Technical Transitions (to Sustainability), and the Multi-Level Perspective." Research Policy 39 (4): 495-510.

Geels, Frank W. 2002. "Technological Transitions as Evolutionary Reconfiguration Processes: A Multi-Level Perspective and a Case-Study." Research Policy 31 (8): 1257-1274.

Geels, Frank W. and Johan Schot. 2007. "Typology of Sociotechnical Transition Pathways." Research Policy 36 (3): 399-417.

Gu, Xin. 2014. "Developing Entrepreneur Networks in the Creative industries-A Case Study of Independent Designer Fashion in Manchester." In Handbook of Research on Small Business and Entrepreneurship, edited by Elizabeth Chell, Mine Karataş-Özkan, 358-373. Cheltenham: Edward Elgar.

Han, Sara L., David J. Tyler, and Phoebe Apeagyei. 2015. "Upcycling as a Design Strategy for Product Lifetime Optimisation and Societal Change." Paper presented at Product Lifetimes And The Environment 2015 Conference, Nottingham, June 17-19.

Han, Sara L., Priscilla YL Chan, Praburaj Venkatraman, Phoebe Apeagyei, Tracy D. Cassidy, and David J. Tyler. 2016. "Standard Vs. Upcycled Fashion Design and Production." Fashion Practice 9 (1): 69-94.

Hart, Stuart L. 1997. "Beyond Greening: Strategies for a Sustainable World." Harvard Business Review 75 (1): 66-77.

Hawkins, Gay. 2001. "Plastic Bags: Living with Rubbish." International Journal of Cultural Studies 4 (1): 5-23. 
Jaitly, Jaya. 1989. "Craft Designs and Development: A Search for Values." Journal of Design History 2 (2/3): 169-174.

Kemp, René and Derk Loorbach. 2006. "5. Transition Management: A Reflexive Governance Approach." In Reflexive Governance for Sustainable Development, edited by Jan-Peter Voß, Dierk Bauknecht and René Kemp, 103-130. Cheltenham: Edward Elgar.

Mair, Simon, Angela Druckman, and Tim Jackson. 2016. "Global Inequities and Emissions in Western European Textiles and Clothing Consumption." Journal of Cleaner Production 132: 57-69.

Margolin, Victor. 1998. "Design for a Sustainable World." Design Issues 14 (2): 83-92. Martin, Michael and Mats Eklund. 2011. "Improving the Environmental Performance of Biofuels with Industrial Symbiosis." Biomass and Bioenergy 35 (5): 1747-1755. McCorkill, Georgia. 2014. "Triangles in Silk: Piecing Together a Practice of Upcycling." Paper presented at Shapeshifting: A conference on Transformative Paradigms of Fashion and Textile Design, Auckland, April 14-16. McDonough, William and Michael Braungart. 2013. The Upcycle: Beyond Sustainability--Designing for Abundance. New York: North Point Press.

Niinimäki, Kirsi and Lotta Hassi. 2011. "Emerging Design Strategies in Sustainable Production and Consumption of Textiles and Clothing." Journal of Cleaner Production 19 (16): 1876-1883.

Packard, Vance. 1963. The Waste Makers. Harmondsworth: Penguin Books.

Palmsköld, Anneli. 2015. "Reusing Textiles: On Material and Cultural Wear and Tear." Culture Unbound: Journal of Current Cultural Research 7 (1): 31-43.

Park, Hyun Hee. 2015. "Clothing \& Textiles: Original Article; the Influence of LOHAS Consumption Tendency and Perceived Consumer Effectiveness on Trust and Purchase Intention regarding Upcycling Fashion Goods." International Journal of Human Ecology 16 (1): 37-47.

Park, Ju Hee and Youn Hee Kim. 2014. "A Study on Fashion Design for Up-Cycled Waste Resources." Journal of the Korean Society of Costume 64 (8): 138-154. Rabionet, Silvia E. 2011. "How I Learned to Design and Conduct Semi-Structured Interviews: An Ongoing and Continuous Journey." The Qualitative Report 16 (2): 563 . 
Rip, Arie and René Kemp. 1998. "Technological Change." In Human Choice and Climate Change, Vol. 2, edited by S. Rayner and E. L. Malone, 327-399. Columbus: Battelle Press.

Robson, Colin. 2011. Real World Research: A Resource for Social Scientists and Practitioner-Researchers. 3rd ed. Vol. 2. Chichester: John Wiley \& Sons Ltd. Rosner, Daniela K. and Kimiko Ryokai. 2009. "Reflections on Craft: Probing the Creative Process of Everyday Knitters." Paper presented at the seventh ACM conference on Creativity and Cognition, Berkeley, October 26-30.

Salvia, Giuseppe., Tim Cooper, Tom Fisher, Luke Harmer, and Christopher Barr. 2015. "What is Broken? Expected Lifetime, Perception of Brokenness and Attitude Towards Maintenance and Repair." Paper presented at Product Lifetimes And The Environment 2015 Conference, Nottingham, June 17-19.

Schor, Juliet. 2000. "Towards a New Politics of Consumption." In The consumer society reader, edited by Juliet Schor, Douglas Holt. New York, NY: The New Press.

Seravalli, Anna. 2016. "Making an Upcycling Station: Makers' Culture, Cross-Sector Collaborations and Citizens' Participation for New Services and Practices within Waste Handling." http://muep.mau.se/handle/2043/21503

Smith, Adrian. 2007. "Translating Sustainabilities between Green Niches and SocioTechnical Regimes." Technology Analysis \& Strategic Management 19 (4): 427450.

Stahel, W. R. 2016. "The Circular Economy." Nature 531 (7595): 435-438.

Sung, Kyungeun. 2015. "A Review on Upcycling: Current Body of Literature, Knowledge Gaps and a Way Forward." Paper presented at the $17^{\text {th }}$ International Conference on Environment, Cultural, Economic and Social Sustainability, Venice, April 13-14.

Sung, Kyungeun . 2017. "Sustainable Production and Consumption by Upcycling: Understanding and Scaling Up Niche Environmentally Significant Behaviour." $\mathrm{PhD}$ diss., Nottingham Trent University.

Sung, Kyungeun and Tim Cooper. 2015. "Sarah Turner-Eco-Artist and Designer through Craft-Based Upcycling." Craft Research 6 (1): 113-122.

Sung, Kyungeun, Tim Cooper, and Sarah Kettley. 2019a. "Developing Interventions for Scaling Up UK Upcycling." Energies 12 (14): 2778.

Sung, Kyungeun, Tim Cooper, and Sarah Kettley . 2018. "Emerging Social Movements for Sustainability: Understanding and Scaling Up Upcycling in the UK." In The 
Palgrave Handbook of Sustainability, edited by Robert Brinkmann and Sandra J. Garren, 299-312, Cham: Palgrave Macmillan.

Sung, Kyungeun, Tim Cooper, and Sarah Kettley . 2019b. "Factors Influencing Upcycling for UK Makers." Sustainability 11 (3): 870.

Sung, Kyungeun, Tim Cooper, and Sarah Kettley . 2014. "Individual Upcycling

Practice: Exploring the Possible Determinants of Upcycling Based on a

Literature Review." Paper presented at Sustainable Innovation 2014 Conference, Copenhagen, November 3-4.

Sung, Kyungeun, Tim Cooper, Usha Ramanathan, and Jagdeep Singh. 2017.

"Challenges and Support for Scaling Up Upcycling Businesses in the UK:

Insights from Small-Business Entrepreneurs." Paper presented at Product

Lifetimes And The Environment 2017 Conference, Delft, November 8-10.

Teli, Mangesh D, Sanket P. Valia, Shailesh Maurya, and Pallavi Shitole. 2014.

"Sustainability Based Upcycling and Value Addition of Textile Apparels." Paper presented at Multidisciplinary Innovation for Sustainability and Growth 2014 Conference, Kuala Lumpur, August 27-28.

Tung, Fang-Wu. 2012. "Weaving with Rush: Exploring Craft-Design Collaborations in Revitalizing a Local Craft." International Journal of Design 6 (3): 71-84.

Twigger Holroyd, Amy. 2012. "Fashion Diggers: Transgressive Making for Personal Benefit." Making Futures 2: 51-61.

Unruh, Gregory C. 2000. "Understanding Carbon Lock-In." Energy Policy 28 (12): 817830.

Van den Bosch, Suzanne JM. 2010. “Transition Experiments: Exploring Societal

Changes Towards Sustainability.” PhD diss., Erasmus University Rotterdam.

Van Weenen, J. C. 1995. "Towards Sustainable Product Development." Journal of

Cleaner Production 3 (1-2): 95-100.

WRAP. 2011. Valuing our Clothes: The Evidence Base.

http://www.wrap.org.uk/sites/files/wrap/10.7

Zhuo, Chuanwei and Yiannis A. Levendis. 2014. "Upcycling Waste Plastics into Carbon Nanomaterials: A Review." Journal of Applied Polymer Science 131 (4): $1-14$. 
${ }^{\text {i }}$ Sung (2017) summarized criteria for (un)sustainable upcycling as follows. Sustainable upcycling means that it: a) avoids another purchase of a new product; b) prolongs the life of the products, giving it a second life; c) avoids unnecessary transport and maintains a small local economy; d) does not require any large amounts of energy; and e) produces products with low environmental impact during usage. Unsustainable upcycling is the process which involves energy intensive process or toxic glues, and does not extend the product lifetime for a significant amount. Questioning whether or not upcycling is a 'good thing' and investigating the limits and/or efficaciousness of upcycling from a sustainability perspective could be the focus of further research on upcycling.

ii These studies on fashion and textile upcycling often cite the research on sustainable product design in the 1990s addressing various sustainable practices including upcycling without using the term, upcycling (e.g., Hart 1997; Van Weenen 1995; Margolin 1998).

iii SMEs are defined by staff headcount and turnover. Micro businesses have staff headcount of less than ten and turnover of equal to or less than $€ 2 \mathrm{~m}$. Small businesses have staff headcount of less than fifty and turnover of equal to or less than $€ 10 \mathrm{~m}$. Medium-sized businesses have staff headcount of less than 250 and turnover of equal to or less than $€ 50 \mathrm{~m}$ (European Commission 2017). 